\title{
A case of right ventricular bronchogenic cyst with the clinical presentation of cerebral infarction and pulmonary embolism
}

Kuniaki Hirai ${ }^{1}$, Naoki Watanabe ${ }^{1}$, Kenji Hisamatsu² ${ }^{2}$ Takafumi Naiki ${ }^{3}$, Eiji Murakami ${ }^{4}$ and Takuji Tanaka ${ }^{1 *}$

*Correspondence: takutt@gmhosp.gifu.gifu.jp

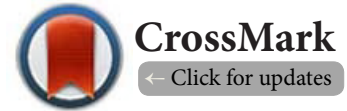

'Department of Diagnostic Pathology (DDP) \& Research Center of Diagnostic Pathology (RC-DiP), Gifu Municipal Hospital, 7-1 Kashima-cho, Gifu City, Gifu 500-8513, Japan.

${ }^{2}$ Department of Tumor Pathology, Gifu University Graduate School of Medicine, 1-1 Yanagido, Gifu City, Gifu 501-1194, Japan.

${ }^{3}$ Department of Central Laboratory, Gifu Municipal Hospital, 7-1 Kashima-cho, Gifu City, Gifu 500-8513, Japan.

${ }^{4}$ Department of Thoracic and Cardiovascular Surgery, Gifu Municipal Hospital, 7-1 Kashima-cho, Gifu City, Gifu 500-8513, Japan.

\begin{abstract}
A congenital malformation of the bronchial tree, known as bronchial cyst, is mostly found in the mediastinum or lung. Intracardiac bronchogenic cysts are quite rare and only two cases of right ventricular bronchogenic cyst have so far been reported. We herein report a case in which a cyst developed in the right ventricle of a 65-year-old Japanese male who presented with aphasia due to cerebral infarction and pulmonary embolism. The cyst was successfully removed and the patient successfully recovered following surgery.
\end{abstract}

Keywords: Bronchogenic cyst, malformation, right ventricule, patent foramen ovale, case report

\section{Introduction}

A bronchogenic cyst is a congenital malformation of the bronchial tree [1]. The cyst usually developed in the mediastinum or lung $[2,3]$. AN intracardiac bronchogenic cyst is therefore an extremely rare malformation [4-7] and only two cases of right ventricular bronchogenic cyst have been reported $[5,6]$. We recently examined right ventricular bronchogenic cyst in a 65-year-old Japanese male who presented at our hospital with aphasia caused by cerebral infarction and pulmonary embolism. The cystic mass was surgically removed. We herein describe the results of the histopathologically and immunohistochemically analyses of the surgically-removed cyst.

\section{Case presentation}

A 65-year-old Japanese male with a history of diabetes was referred to our hospital due to aphasia. A neurological examination revealed aphasia and a mild disturbance of consciousness. Data from other physiological examinations, including those for blood pressure, pulse rate, respiratory rate, and temperature were within the normal limits. Auscultatory findings were normal for the lung and heart. The abdomen was soft and flat and no tenderness was observed. There was no peripheral edema.

A large, high intensity lesion in the left middle cerebral arterial territory was detected on diffusion weighted images during brain magnetic resonance imaging (MRI) (Figure 1). Transthoracic echocardiography revealed a mass in the right ventricle and small left ventricle due to right ventricular enlargement. Transesophageal echocardiography showed no shunt or thrombus in the left atrium and ventricle. A contrast enhanced computed tomography (CT) scan revealed a cystic mass in the right ventricle (Figure 2) and a thrombus in the right pulmonary arteries (Figure 3). Cardiac MRI detected a cystic mass arising from the interventricular septum in the right ventricle. It had an intermediate and high signal intensity on $\mathrm{T} 1$ and $\mathrm{T} 2$ weighted spin-echo images, respectively (Figures $4 \mathbf{a}$ and $\mathbf{4 b}$ ).

Based on these findings, the patient was diagnosed with cerebral infarction and pulmonary embolism. The right ventricular mass was considered to be a cardiac myxoma. We could not determine whether the right ventricular mass was related to the cerebral infarction because an atrial septal defect and/ or a ventricular septal defect shunt were not radiographycally observed in the heart.

Soon after the diagnosis, the patient received cere-bro-protection

(c) 2015 Tanaka et al; licensee Herbert Publications Ltd. This is an Open Access article distributed under the terms of Creative Commons Attribution License (http://creativecommons.org/licenses/by/3.0). This permits unrestricted use, distribution, and reproduction in any medium, provided the original work is properly cited. 


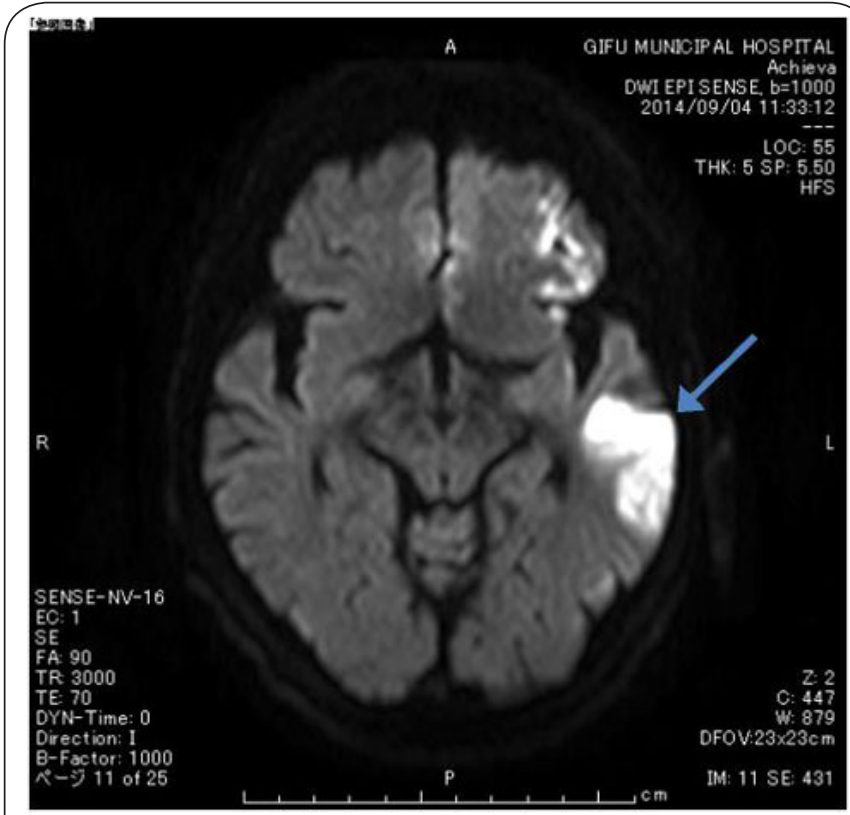

Figure 1. Magnetic resonance images showing a left cerebral infarction (arrow).

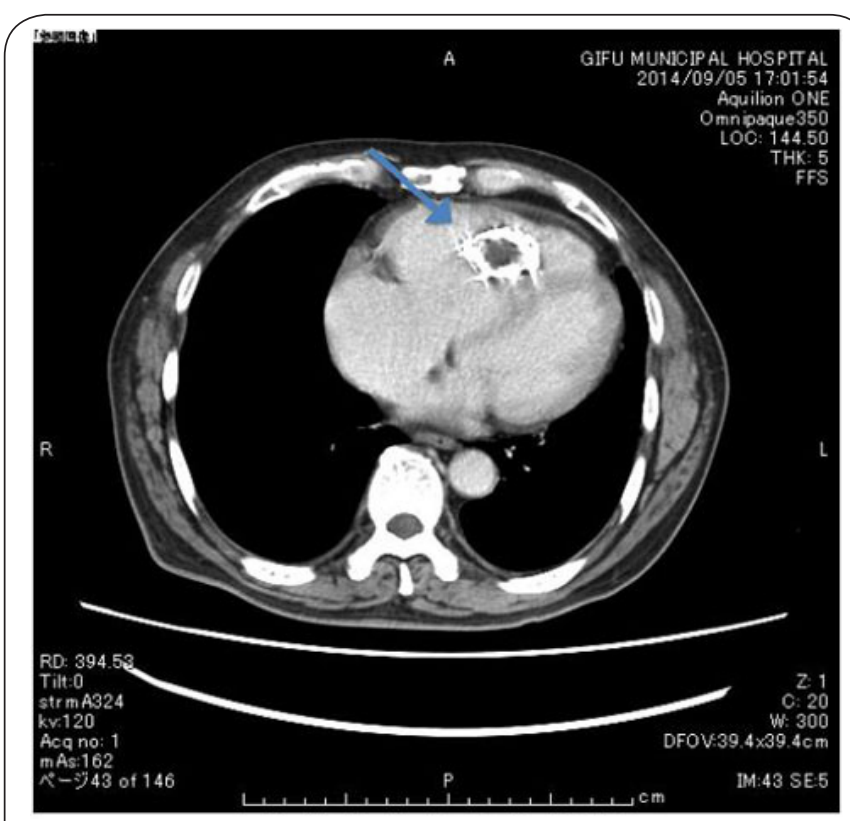

Figure 2. A contrast enhanced computed tomography scan showing a cystic mass (arrow) in the right ventricular.

and anti-coagulant therapies. One month later, surgical excision of the cardiac mass under extracorporeal circulation was performed. The right atrium was opened and a round mass suggestive of a cystic lesion ( $4 \mathrm{~cm}$ in diameter) arising from the interventricular septum was detected in the right ventricle.

A $5 \mathrm{~mm}$ patent foramen ovale was incidentally found. The cystic lesion surrounded by fibrin materials like thrombi protruded from the lumen of the right ventricle. It was successfully resected, and the patent foramen ovale was closed.

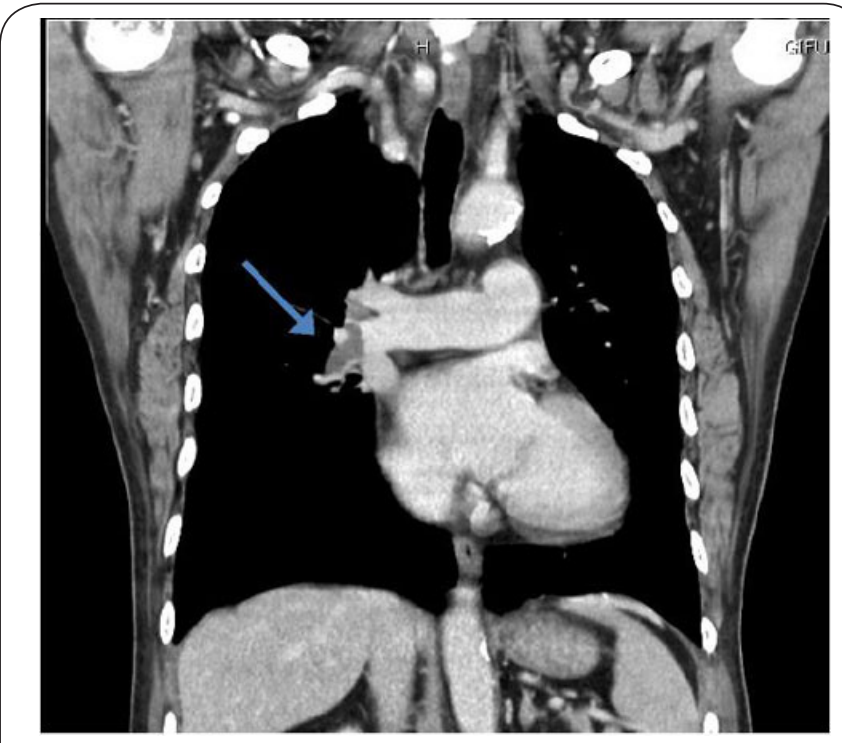

Figure 3. A contrast enhanced computed tomography scan showing a thrombus (arrow) in the right pulmonary artery.

Histopathologically, the wall of the cystic lesion was lined with ciliated columnar epithelia. Bronchial glands were present under the epithelia, suggesting this was a bronchogenic cyst (Figures $\mathbf{5}$ and $\mathbf{6 a}$ ). Smooth muscle and fibrous tissue with severe hyalinization and calcification were present in the cyst wall. To confirm our diagnosis of bronchogenic cyst, immunohistochemical analyses using antibodies against thyroid transcription factor (TTF)-1, CK7, Ber-Ep4, calretinin, MUC1, MUC2, MUC5AC, MUC6, synaptophysin and villin were performed. The results indicated the columnar epithelium lining the cyst wall was positive for TTF-1 (Figure 6b) and CK7 (Figure 6c), but negative for CK20 (Figure 6d), MUC1 (Figure 7a), MUC2 (Figure 7b), MUC5AC (Figure 7c), MUC6 (Figure 7d), BerEp4 (Figure 7e), calretinin (Figure 7f), synaptophysin (Figure 7g) and villin (Figure $7 \mathrm{~h}$ ).

The patient recovered well from surgery and was discharged 16 days post-operation. As of the writing this manuscript, he remains asymptomatic.

\section{Discussion and conclusion}

We herein presented a rare case of a bronchogenic cyst in a Japanese male. Bronchogenic cysts mostly develop in the mediastinum and lung [2,3]; however, intracardiac bronchogenic cysts are extremely rare [4-7]. To the best of our knowledge, there are only two other reports published in English on right ventricular bronchogenic cyst $[5,6]$.

The location of the bronchogenic cyst can be explained by embryogenesis [1]. Bronchogenic cyst arises from abnormal buds from the primitive esophagus and tracheobronchial tree, which do not extend to the site where alveolar differentiation occurs. Cardiac primordial exist in a place very near to the foregut or primitive tracheobronchial tree. At this time, abnormal budding of the tracheobronchial tree may migrate 

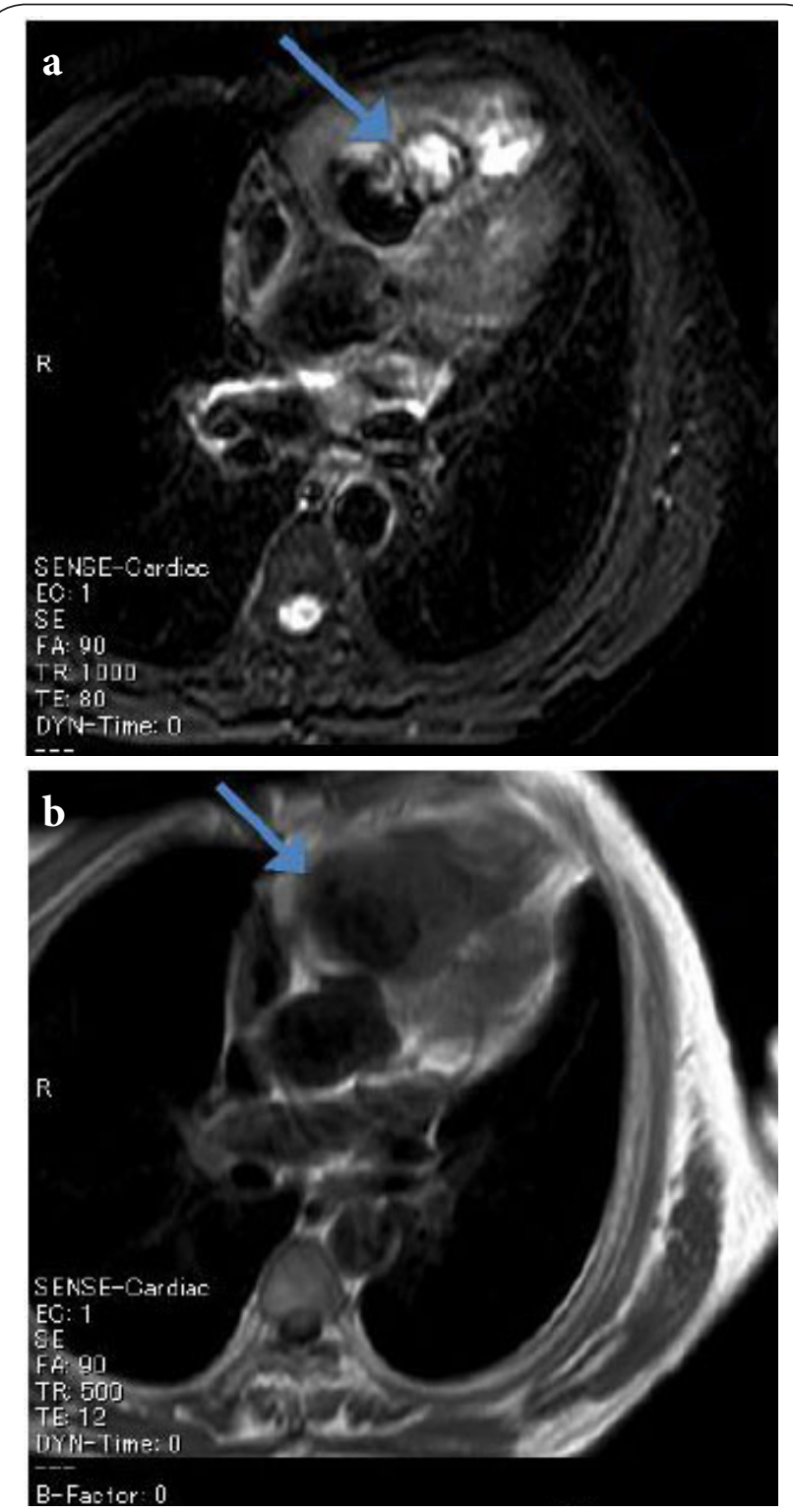

Figure 4. Cardiac magnetic resonance images showing a cystic mass (arrow) arising from the interventricular septum in the right ventricle. The cystic mass has an intermediate signal intensity on a T1 weighted spin-echo image (a) and a high signal intensity on a T2 weighted spin-echo image (b).

to myocardium [4].

Clinical presentations of cardiac bronchogenic cyst are variable, ranging from asymptomatic patients to those with dyspnea, palpitations, or pre-syncope $[3,8]$. In the present case, fibrinous thrombi attached to the right ventricular cyst might have caused pulmonary embolism, resulting in pulmonary hypertension. Additionally, thrombi of the right ventricle migrated past the patent foramen ovale and caused cerebral infarction. Associated lesions reported in previous cases of intracardiac bronchogenic cyst include atrial septal defect $[9,10]$, but notpatent foramen ovale.

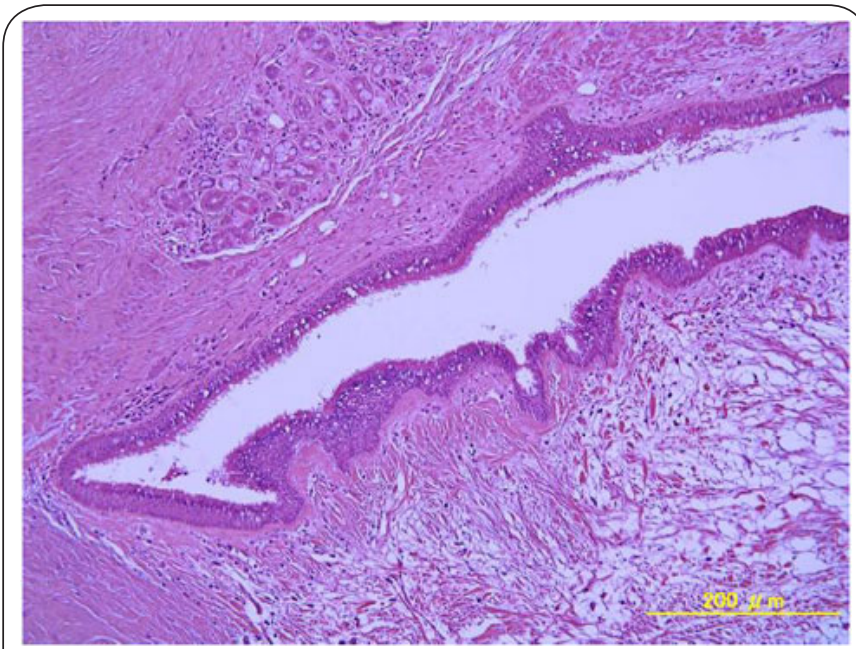

Figure 5. A histopathological analysis of the cystic mass. The cyst is lined by ciliated columnar cells and glands are present in the cyst wall. Hematoxylin and eosin staining, bar $=200 \mu \mathrm{m}$.

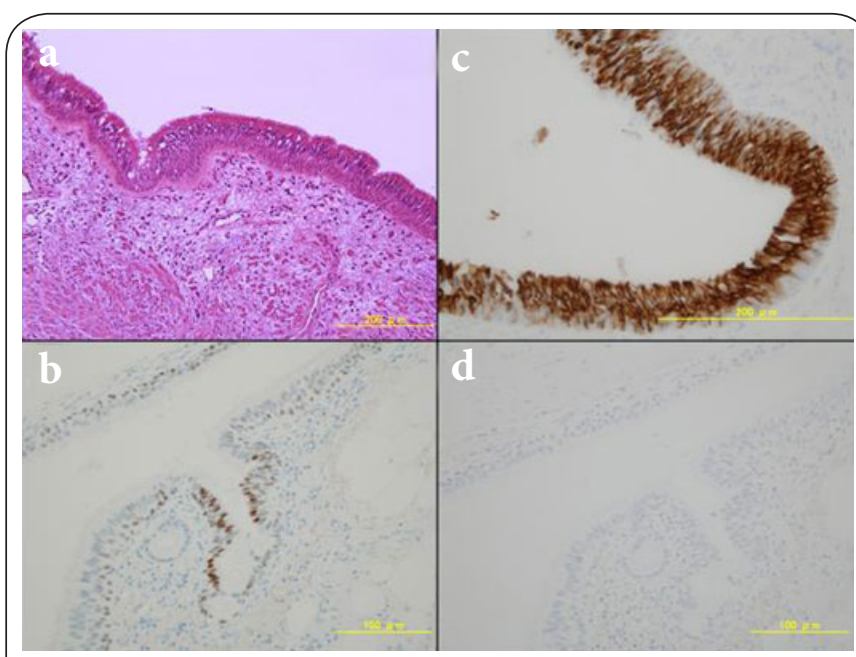

Figure 6. Fistopathological (a) and immunohistochemical (b, c and d) analyses of the cystic mass. Some nuclei of ciliated columnar epithelium (a) are positive for TTF-1 (b). The cytoplasm is strongly positive for CK7 (c), but negative for CK20 (d). Hematoxylin and eosin staining (a) and immunohistochemical analyses $(\mathbf{b}-\mathbf{d})$, bars $=(\mathbf{a}, \mathbf{c}) 200 \mu \mathrm{m}$; and $(\mathbf{b}, \mathbf{d}) 100 \mu \mathrm{m}$.

Most intracardiac bronchogenic cysts have been found by transthoracic echocardiography [7]. Echocardiography is able to provide accurate determinations of size, location, point of attachment, mobility, and hemodynamic relevance. A diagnosis is made by contrast-enhanced chest $\mathrm{CT}$ and cardiac MRI, which provides a non-invasive method of obtaining 3-dimensional images of masses involving the cardiac chambers and pericardium. As observed in our case, a bronchogenic cyst has an intermediate and high signal intensity on $\mathrm{T} 1$ and $\mathrm{T} 2$ weighted spin-echo images, respectively [10].

Bronchogenic cysts with an average diameter of 3 to 4 
Hirai et al. Pathology Discovery 2015,
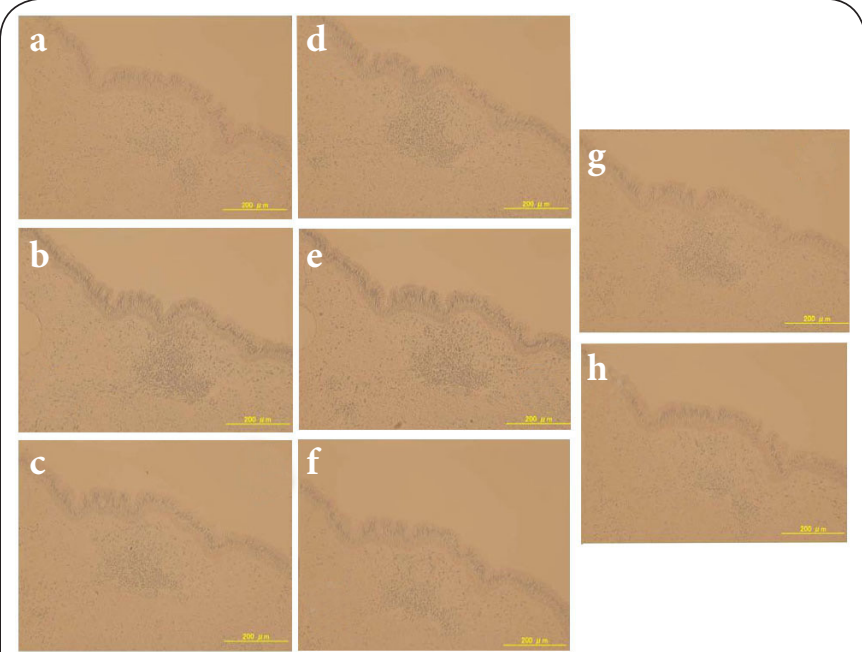

Figure 7. Immunohistochemical analyses of the cystic mass. Ciliated columnar epithelium is negative for MUC1 (a), MUC2 (b), MUC5AC (c), MUC6 (d), Ber-Ep4 (e), calretinin (f), synaptophysin (g) and villin (h). Immunohistochemical analyses, bars $=200 \mu \mathrm{m}$.

$\mathrm{cm}$ contain clear or gelatinous fluid. Microscopically, they usually are lined with ciliated columnar epithelia with focal or extensive squamous metaplasia and/or extreme attenuation of this lining can occur. The wall may contain hyaline cartilage, smooth muscle, bronchial glands, and nerve trunks. In our bronchogenic cyst, there were ciliated columnar epithelia without squamous metaplasia. We did not observe any other tissues or any cartilage, or nerves. According to immunohistochemical analyses we determined the ciliated columnar cells to be bronchial epithelia positive for TTF-1 and CK7, and negative for CK20 [11].

\section{Competing interests}

The authors declare that they have no competing interests.

\section{Authors' contributions}

\begin{tabular}{|l|c|c|c|c|c|c|}
\hline Authors' contributions & KH & NW & KH2 & TN & EM & TT \\
\hline Research concept and design & $\checkmark$ & $\checkmark$ & $\checkmark$ & -- & -- & $\checkmark$ \\
\hline Collection and/or assembly of data & $\checkmark$ & $\checkmark$ & $\checkmark$ & $\checkmark$ & $\checkmark$ & $\checkmark$ \\
\hline Immunohistochemistry & -- & $\checkmark$ & $\checkmark$ & -- & -- & -- \\
\hline Data analysis and interpretation & $\checkmark$ & $\checkmark$ & $\checkmark$ & $\checkmark$ & $\checkmark$ & $\checkmark$ \\
\hline Writing the article & $\checkmark$ & $\checkmark$ & -- & -- & -- & $\checkmark$ \\
\hline Critical revision of the article & $\checkmark$ & -- & -- & -- & -- & $\checkmark$ \\
\hline Final approval of article & $\checkmark$ & $\checkmark$ & $\checkmark$ & $\checkmark$ & $\checkmark$ & $\checkmark$ \\
\hline
\end{tabular}

\section{Acknowledgement}

This work was supported in part by the Grant of JSPS KAKENNHI (no. 22790638).

\section{Publication history}

Editors: Hiroko Kuwabara, Osaka Medical College, Japan.

Vaclav Vetvicka, University of Louisville, USA.

EIC: Markus H. Frank, Harvard Medical School, USA.

Received: 12-Jan-2015 Final Revised: 20-Feb-2015

Accepted: 25-Feb-2015 Published: 28-Feb-2015

\section{References}

1. Rios LT, Araujo Junior E, Nardozza LM, Moron AF and Martins Mda G. Prenatal diagnosis and postnatal findings of bronchogenic cyst. Case Rep Pulmonol. 2013; 2013:483864. | Article | PubMed Abstract | PubMed Full Text

2. Esme H, Eren S, Sezer M and Solak O. Primary mediastinal cysts: clinical evaluation and surgical results of $\mathbf{3 2}$ cases. Tex Heart Inst J. 2011; 38:371-4. | PubMed Abstract | PubMed Full Text

3. Sarper A, Ayten A, Golbasi I, Demircan A and Isin E. Bronchogenic cyst. Tex Heart Inst J. 2003; 30:105-8. I PubMed Abstract I PubMed Full Text

4. Jiang $\mathrm{H}$, Wang $\mathrm{H}, \mathrm{Wu} \mathrm{H}$ and $\mathrm{Li} X$. Bronchogenic cyst of the interatrial septum. J Cardiothorac Surg. 2013; 8:171. | Article | PubMed Abstract | PubMed Full Text

5. Prates PR, Lovato L, Homsi-Neto A, Barra M, Sant'Anna JR, Kalil RA and Nesralla IA. Right ventricular bronchogenic cyst. Tex Heart Inst J. 2003; 30:71-3. | PubMed Abstract | PubMed Full Text

6. Weinrich M, Lausberg HF, Pahl S and Schafers HJ. A bronchogenic cyst of the right ventricular endocardium. Ann Thorac Surg. 2005; 79:e13-4. I Article I PubMed

7. Ogunkunle $\mathrm{OO}$ and Animashaun D. Intracardiac bronchogenic cyst in a 2-year-old Nigerian boy. BMJ Case Rep. 2012; 2012. I Article I PubMed Abstract | PubMed Full Text

8. Michels $\mathrm{G}$, Bovenschulte $\mathrm{H}$, Drebber $\mathrm{U}$ and Pfister R. Bronchogenic cyst mimicking ischemic heart disease. Lung India. 2012; 29:376-7. | Article | PubMed Abstract I PubMed Full Text

9. Borges AC, Knebel F, Lembcke A, Panda A, Komoda T, Hiemann NE, Meyer $R$, Baumann $G$ and Hetzer R. Bronchogenic cyst of the interatrial septum presenting as atrioventricular block. Ann Thorac Surg. 2009; 87:1920-3. | Article | PubMed

10. Roos-Hesselink JW, Verhoeven GT and Stoker J. Bronchogenic cyst mimicking an intracardiac mass: diagnosis by magnetic resonance imaging and treatment by needle aspiration. Heart. 1996; 75:639. | Article | PubMed Abstract | PubMed Full Text

11. Soilleux EJ and Davies DR. Epithelial cyst of the cardiac papillary muscle: case report and review of the literature. J Clin Pathol. 2006; 59:1203-5. I Article | PubMed Abstract | PubMed Full Text

\section{Citation:}

Hirai K, Watanabe N, Hisamatsu K, Naiki T, Murakami E and Tanaka T. A case of right ventricular bronchogenic cyst with the clinical presentation of cerebral infarction and pulmonary embolism. Pathol Discov. 2015; 3:2. http://dx.doi.org/10.7243/2052-7896-3-2 